\title{
Electrochemical Determination of Carbon-Carbon Double Bond Containing Pesticide Residues in Environmental Matrices
}

\author{
Thommandru Raveendranath Babu, Puchakayala Sujana and Sarvareddy Rajasekhar Reddy* \\ Department of Chemistry, NBKR Science and Arts College, India
}

Submission: March 04, 2017; Published: August 24, 2017

*Corresponding author: Sarvareddy Rajasekhar Reddy, Electro analytical Lab, Department of Chemistry, NBKR Science and Arts college, vidyanagar Nellore dist, AP, India, Email: sekharreddydr02@gmail.com

\begin{abstract}
In this approach we have chosen differential pulse adsorptive stripping voltammetry as a method of analysis to develop a standard procedure based on reduction characteristics of $>\mathrm{C}=\mathrm{C}<$ the pesticides phenothrin and binapicryl at carbon nano tubes paste electrodes for the determination of residues in environmental matricies. Electrode mechanism studied by using cyclic voltametry and number of electron was found by using milliculometry and the reduction product collected by using controlled potential electrolysis. Universal buffer solution with $\mathrm{pH}$ range 2.0 to 6.0 used as supporting electrolyte. The optimum $\mathrm{pH}$ to get well-defined peak for the detection is found to be 4.0.Calclations made by following standard addition method. The peak heights are in linear trend over the concentration range of $1.0 \times 10^{-8}$ to $1.0 \times 10^{-5} \mathrm{M}$ for phenothrin and $3.0 \times 10^{-8} \mathrm{M}$ to $1.0 \times 10^{-4}$ for binapicryl. The relative standard deviation and correlation coefficient for phenothrin is $0.97 \%$ and 0.998 and standard deviation and correlation coefficient were found to be $0.95 \%$ and 0.994 for binapicryl. The lower detection limit for phenothrin was $0.92 \times 10^{-7} \mathrm{M}$ and $0.89 \times 10^{-6} \mathrm{M}$ for binapicryl.
\end{abstract}

Keywords: Differential pulse adsorptive stripping voltammetry; Cyclic voltammetry; Carbon nano tubes paste electrodes; Universal buffer solution; Grain samples

\section{Introduction}

Pyrethroids are highly effective insecticides used forthe control of a wide spectrum of insect pests, in agriculture, public areas and households EP Yúfera et al. [1]. Unfortunately pyrethroids are highly toxic to a number of non-target organisms such as bees, fresh water fish and other aquatic organisms even at very low concentrations L Somasundaram et al. [2]. The fate of synthetic pyrethroids is very important from a toxicological point of view due to their persistence in the field RM Perin et al. [3] and also due to their relative bioaccumulation HC Oudou et al. [4]. In the present investigation, agriculturally important $>\mathrm{C}=\mathrm{C}<$ group containing pesticides phenothrin and binapicryl were selected.

\section{Phenothrin}

phenothrin is broad spectrum pyrithroid ester insecticide which is widely used for weed control in many agricultural crops. For the determination of phenothrinrecidues in environmental samples and biological samples different analytical techniques were reported. Sioufi et al. [5] Determined pyrethroids in plasma and urine by high-performance liquid chromatography. Anton $\mathrm{K}$ et al. [6] performed Supercritical fluid chromatography in the routine stability control of antipruritic preparations. Economical (reduction of analysis time, fewer experimental steps and less sample pre-separation) and ecological (carbon dioxide of organic solvents) advantages make SFC an attractive alternative to liquid chromatography in the determination of phenothrin. $\mathrm{H}$ Nishi et al. [7] explained Pharmaceutical applications of micelles in chromatography and electrophoresis. Schulz et al. [8] subjected combined liquid chromatography time of flight mass spectrometry for water screening with software tools to identify pesticides and their metabolites.

\section{Binapacryl}

Binapicryl is registered as dinitrophenolacaricide (bird repellenent) Taccheo Barbina et al. [9] determined pesticide by using Solid-phase extraction and gas chromatographic determination acaricide residues in honey. Bissacot et al. [10] applied HPLC determination of binapicryl, deltamethrin, cypermethrin, and cyhalothrin residues in the milk and blood of lactating dairy cows. Sassine et al. [11] employed cypermethrin 
Residues Determination in the Milk of a Lactating Dairy Cow by Gas Chromatography-Ion Trap Mass Spectrometry. Ravi et al. [12] employed Negative Ion Chemical Ionization- Gas Chromatographic-Mass Spectrometric Determination of Residues of Different pesticides in Whole Blood and Serum. Wang et al. [13] subjected Chromatographic methods for the determination of pesticide residues in crops, foods and environmental samples. Sanghavi et al. [14-18] reported voltametric determination of pesticides having various electro active groups drugs and metals.

\section{Experimental}

Apparatus and electrodes: The electrochemical measurements were carried out with Metrohm model 101 potentiostat and galvanostat. The three-electrode system consisted of carbon nanotubes paste electrode as the working electrode, $\mathrm{Ag} / \mathrm{AgCl}$ reference electrode and a platinum wire auxiliary electrode. The electrodes joined the cell through holes in its Teflon cover. All of the potentials given in this work were measured with respect to this reference system. Electrochemical experiments were carried out in a voltammetric cell at room temperature. A magnetic stirrer was used during the accumulation step. The Elico Li-129 model glass calomel combined electrode was employed for measuring $\mathrm{pH}$ values.
Preparation of carbon nanotubes paste electrode: The CNTPE was prepared by mixing multiwall CNTs powder (diameter $20-50 \mathrm{~nm}$, either $1-5 \mathrm{~mm}$ or $5-20 \mathrm{~mm}$ lengths) and Castrol oil in an agate mortar at a ratio of $50.0 \%(\mathrm{w} / \mathrm{w})$ each. A portion of the resulting paste was packed firmly into the cavity (0.8mm diameter) of a Teflon tube. The electrical contact was established via a copper wire.

Reagents and solutions: All reagents used were of analytical reagent grade. Double distilled water was used throughout the analysis. In the present investigation, universal buffers in the $\mathrm{pH}$ range 2.0 to 6.0 were used as supporting electrolytes and were prepared using $0.2 \mathrm{M}$ boric acid, $0.05 \mathrm{M}$ citric acid and $0.1 \mathrm{M}$ trisodium orthophosphate solutions. Samples were obtained from bayer crop, India, Ltd.

\section{Result and Discussion}

\section{Characterisation of peaks/waves}

Binapycril and phenothrin was found to a give a single well defined peak in acidic solutions $(2<\mathrm{pH}<6)$. Increase of $\mathrm{pH}$ from 4.0 leads to decrease of the peak current. In the acidic medium, the peak of the compound is due to the reduction of $\mathrm{C}=\mathrm{C}$ group in two electron process. Typical cyclic voltammogram of binapicryl is shown in Figure 1.
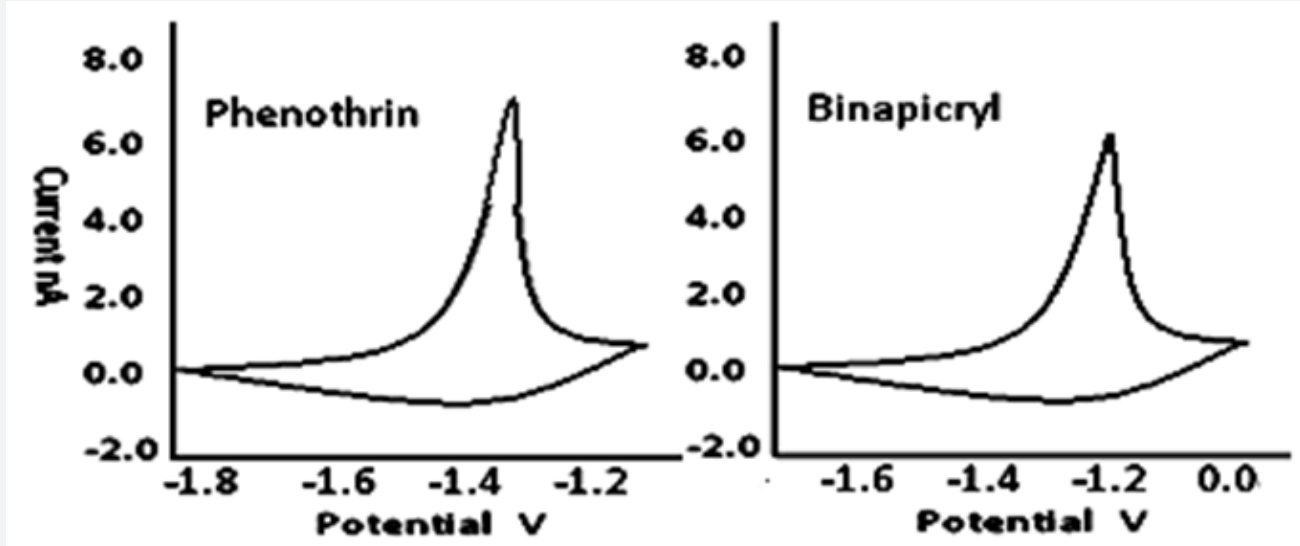

Figure 1: Typical cyclic voltammogram of phenothrin and binapicryl at CNTPE, pH 4.0 concentration: $0.5 \mathrm{mM}$; scan rate : $45 \mathrm{mVs} \mathrm{s}^{-1}$.
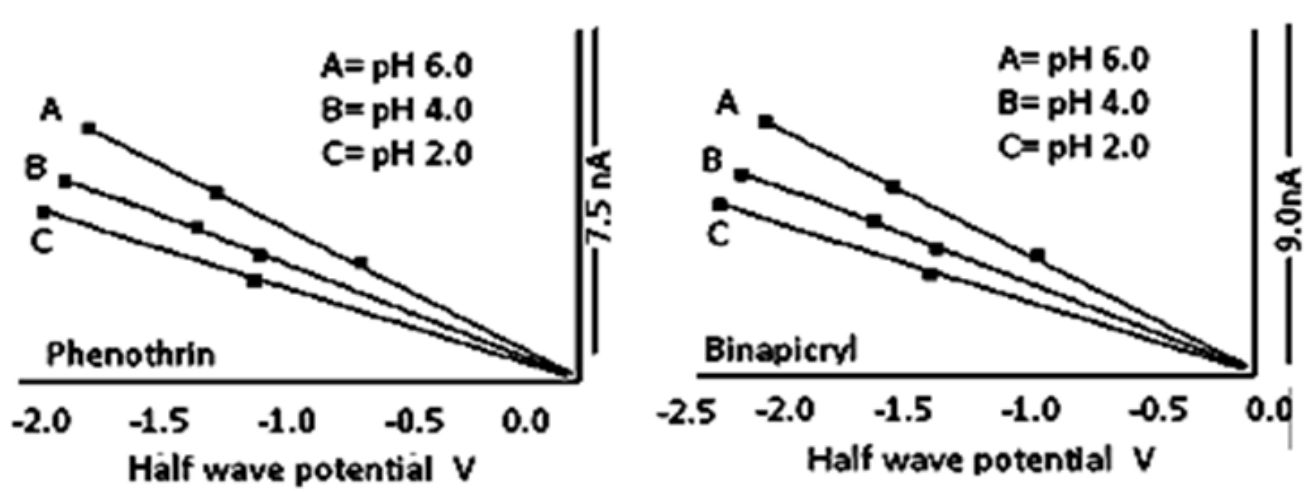

Figure 2: $\mathrm{i}_{\mathrm{p}}$ vs $\mathrm{V}^{1 / 2}$ plot of phenothrin and binapicryl concentration: $0.5 \mathrm{mM}$, scan rate: $45 \mathrm{mVs}^{-1}$. 


\section{Nature of the electrode process}

The reduction process in Binapycril and phenothrin was found to be diffusion controlled and adsorption on the electrode surface in the buffer systems studied as evidenced from linear plot $i_{p} v s v^{1 / 2}$ passing through origin (Figure 2) The shift of peak potential $\left(E_{p}\right)$ towards more negative values with increase in concentration of depolarizer, shows that the electrode process is irreversible. This is further confirmed by log-plot analysis. The variation of peak potentials with scan rates and absence of anodic peak in the reverse scan in cyclic voltammetry indicates the irreversible nature of the electrode processes. The dependence of $\mathrm{i}_{\mathrm{p}} / \mathrm{pH}$ curves shows a behaviour in accordance

Table1: Typical cyclic voltammetric data of of phenothrin and binapicryl concentration: $0.5 \mathrm{mM}$, scan rate: $45 \mathrm{mVs}^{-1}$.

\begin{tabular}{|c|c|c|c|c|c|c|}
\hline Sample & pH & Ep/V & Current/nA & $\alpha$ na & $\mathrm{DX}^{2} 0^{6} / \mathrm{cm}^{2} \mathrm{sec}^{-1}$ & k0fh $\mathrm{cm} \mathrm{sec}^{-1}$ \\
\hline Phenothrin & 4.0 & 1.45 & 6.5 & 0.42 & 1.28 & $3.92 \times 10^{-10}$ \\
\hline Binapicryl & 4.0 & 1.34 & 6.0 & 0.34 & 1.68 & $2.23 \times 10^{-12}$ \\
\hline
\end{tabular}

\section{Kinetic data}

Kinetic data such as diffusion coefficient, transfer coefficient and heterogeneous forward rate constants obtained with different methods for Binapycril and phenothrin are summarised in Table 1. The diffusion coefficient values were noticed to be in with a process in which a proton transfer provides the reduction of the acid form to form an electro active species. The number of

\section{Identification of reduction products}

Millicoulometry was employed to find out the number of electrons involved in the electrode process. The results obtained from millicoulometry have shown that the number of electrons is two for Binapycril and phenothrin. The number of protons involved in the rate determining step of the electrode process is two. Controlled potential electrolysis experiments were carried out at $-0.8 \mathrm{~V}$ vs. SCE at pH 4.0. The reduction products were confirmed by I.R. spectral data. protons taking part in the rate determining step is two.

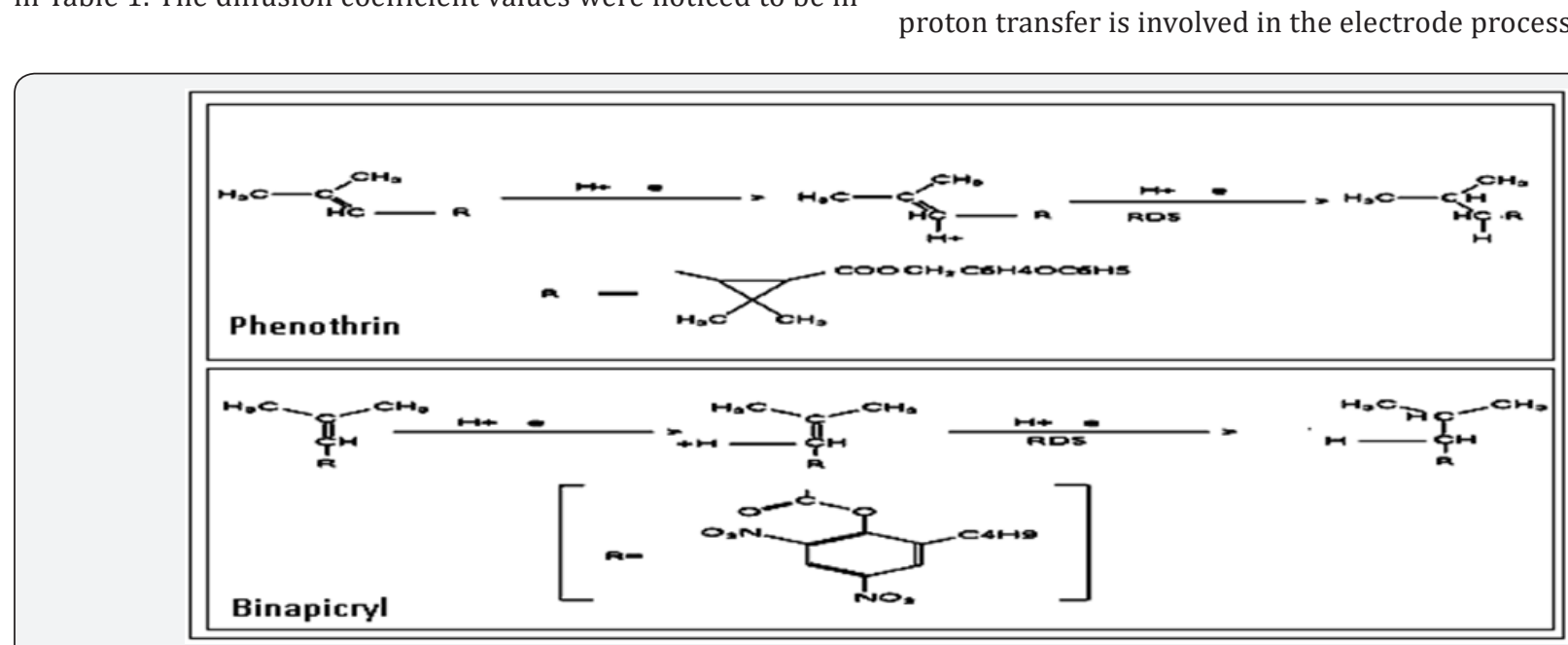

Scheme I: Reduction mechanism proposed for Binapycril and phenothrin in entire $\mathrm{pH}$ range.

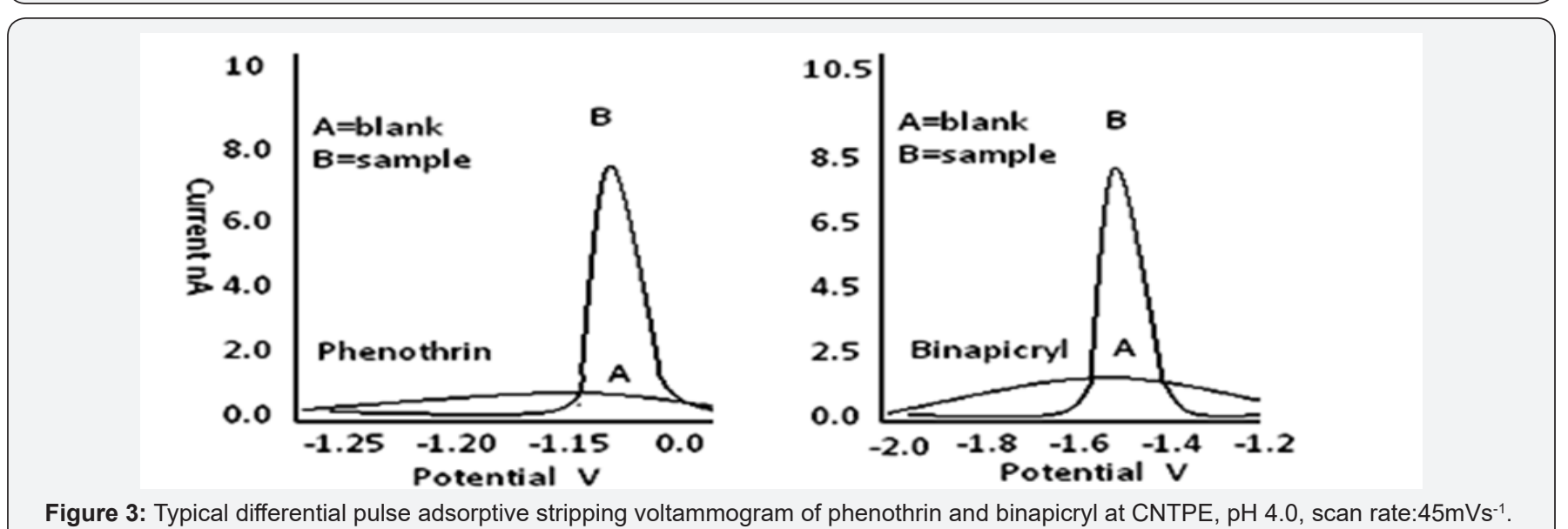


Differential pulse-adsorptive stripping voltammetric studies

DP-AdSV peak of phenothrin and binapicryl at CNTPE (Figure 3 ) is attributed to two electron reduction of binapicrylThis peak followed to establish the optimum conditions. The standard addition and calibration methods have been employed to estimate the compound in water and soil samples.
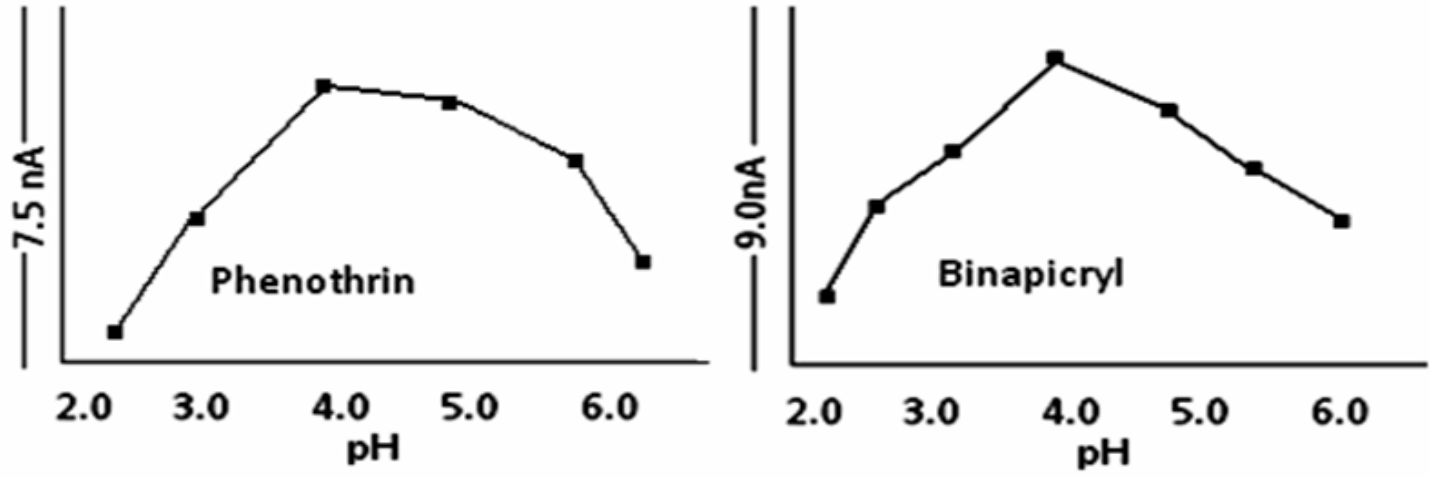

Figure 4: Effect of $\mathrm{pH}$ on the reduction potentials of phenothrin and binapicryl at CNTPE.

\section{Effect of pH}

During the analysis the dependence of peak currents at CNTPE on $\mathrm{pH}$ of supporting electrolyte were studied for $1.0 \times 10$ ${ }^{5} \mathrm{M}$ phenothrin and binapicryl with accumulation time $60 \mathrm{sec}$. respective electrode between $\mathrm{pH} 2.0$ to 6.0. It can be observed from Figure 4. That the maximum peak potentials were obtained with $\mathrm{pH}$ 4.0. The shift of the peak potentials towards more negative values indicating proton participation in the reduction process.
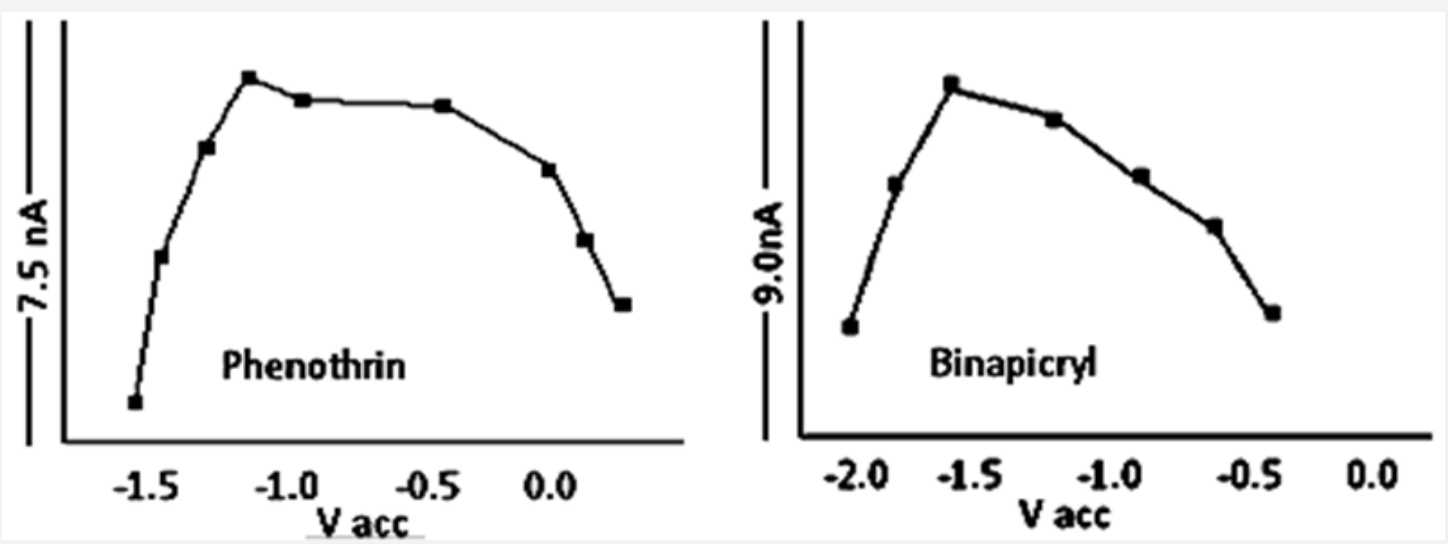

Figure 5: Effect of accumulation potential on the DP-AdSV response of phenothrin and binapicryl at CNTPE.

\section{Effect of accumulation potential}

Dependence of AdSV signal on accumulation potential were studied with accumulation time of $60 \mathrm{sec}$. at CNTPE for 1.0x10 ${ }^{5} \mathrm{M}$ phenothrin and binapicryl solution. From Figure 5 it is observed that $\mathrm{i}_{\mathrm{p}}$ value for $-0.9 \mathrm{~V}$ at $\mathrm{pH} 4.0$ because of an increase accumulation rate, due to the more favourable alignment of molecules by the electric field at the electrode solution interface.

\section{Effect of accumulation time}

Figure 6 shows plot of cathodic peak current for adsorptive stripping voltammetry against accumulation time $\left(t_{\text {acc }}\right)$ for different concentrations of phenothrin and binapicryl. At first, peak current increased linearly with $t_{\text {acc }}$ indicating that before adsorptive equilibrium reached, the longer the pre-concentration time, the more the phenothrin and binapicryl were adsorbed and larger the peak current. However, after $80 \mathrm{sec}$., the peak current tended to level off, illustrating that adsorptive equilibrium o phenothrin and binapicryl on the mercury electrode surface was achieved.

\section{Effect of scan rate}

The effects of varying the potential scan rate on the reduction peak current of phenothrin and binapicryl were examined. The reduction peak current increases linearly with scan rate over the range from $20 \mathrm{mVs}^{-1}$ to $60 \mathrm{mVs}^{-1}$ as expected for the reduction of binapicryl being adsorbed. Best sensitivity was achieved at a scan rate of $50 \mathrm{mVs}^{-1}$ for phenothrin and binapicryl. 

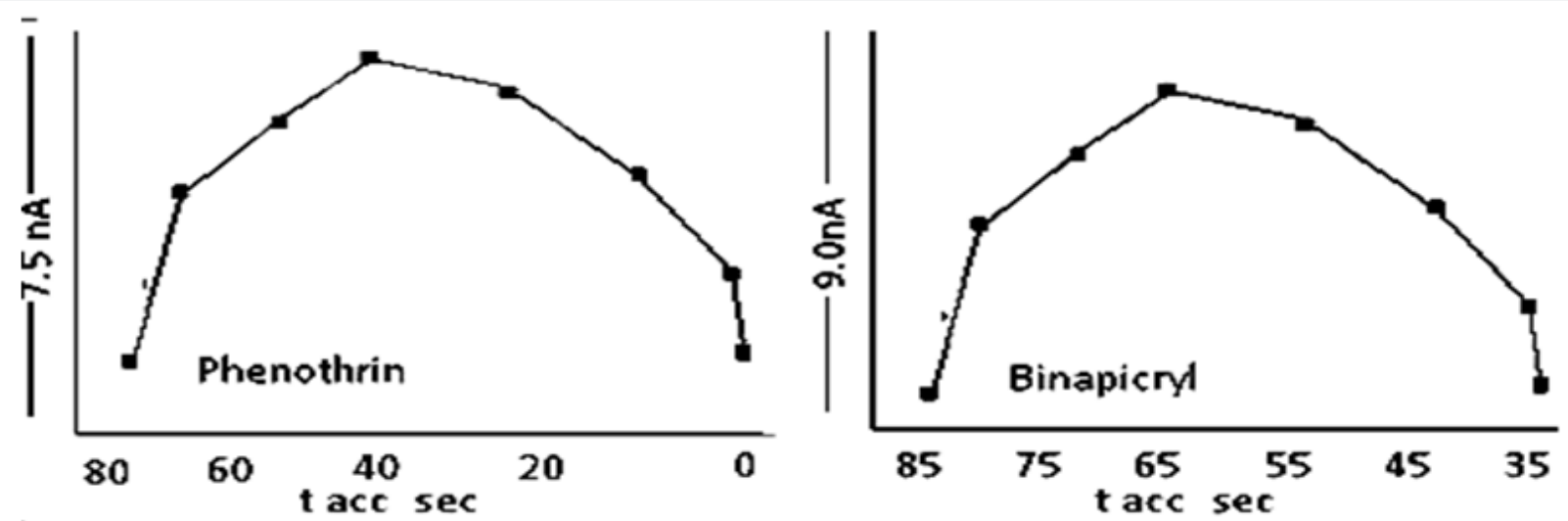

Figure 6: Effect of accumulation time on the DP-AdSV response of of phenothrin and binapicryl at CNTPE.

\section{Recovery Experiments}

\section{Analysis}

Well defined and well resolved AdSV waves/peaks ofphenothrin and binapicrylobtained at $\mathrm{pH} 4.0$ were used for the quantitative estimation of phenothrin and binapicryl in water and soil samples. Both calibration and standard addition methods were used for the quantitative determination of the phenothrin and binapicryl. From the calibration method, it is observed that the peak current shows a trend found to be linear over the concentration range $3.0 \times 10^{-8} \mathrm{M}$ to $1.0 \times 10^{-4}$ with lower detection limit $0.89 \times 10^{-6} \mathrm{M}$ for phenothrin and binapicryl for 6 replicates, relative standard deviation and correlation coefficient were found to be $0.95 \%$ and 0.994 respectively for phenothrin and binapicryl.

\section{Recommended analytical procedure}

The stock solution $\left(1.0 \times 10^{-3} \mathrm{M}\right)$ of phenothrin and binapicryl is prepared by dissolving the required quantity of the electro active species in methanol. Standard solutions were prepared by dilution of stock solution with suitable amount of methanol. $1 \mathrm{~mL}$ of the standard solution is transferred into voltammetric cell and added with $9 \mathrm{~mL}$ of the supporting electrolyte and then deoxygenated by bubbling oxygen free nitrogen gas for $10 \mathrm{~min}$.
After recording the voltammogram, small increments of standard solutions $(0.2 \mathrm{~mL})$ were added and then voltammograms recorded for each addition under similar experimental conditions. The optimum conditions for the analytical determination of phenothrin and binapicryl at $\mathrm{pH} 4.0$ are found to be drop time of $2 \mathrm{sec} .$, pulse amplitude of $25 \mathrm{mV}$ and applied potential of $-0.90 \mathrm{~V}$ for phenothrin and binapicryl.

\section{Determination of phenothrin and binapicryl in spiked grain samples}

The developed analytical procedure has been applied to the quantitative estimation of phenothrin and binapicryl in grain samples. Known amounts of phenothrin and binapicryl were sprayed on grain (wheat, rice) samples $(25 \mathrm{~g})$ and left for 1-2 hours. Then the samples are weighed, crushed and homogenized. The extracts were prepared by treatment of the above sample with two $50 \mathrm{~mL}$ portions of acetone and evaporated to dryness. The residue of phenothrin and binapicryl dissolved in methanol and transferred to a $100 \mathrm{~mL}$ volumetric flask. Results obtained for the determination of phenothrin and binapicryl in grains by DP-AdSV method, range from 98.00 to $99.16 \%$ are obtained for two samples for 10 replicates indicates the high accuracy and reproducibility of the proposed DP-AdSV method. The results are summarized in Table 2.

Table 2: Recoveries of phenothrin and binapicryl in spiked grain samples.

\begin{tabular}{|c|c|c|c|c|c|}
\hline Grains & Sample & Amount Added $\boldsymbol{\mu g L}^{-1}$ & ${\text { Amount Found } \boldsymbol{\mu g L}^{-1}}^{*}{ }^{*}$ Recovery $\%$ & SD & 0.0212 \\
\hline \multirow{2}{*}{ Black gram } & A & 2.0 & 1.96 & 98.00 & 0.0252 \\
\cline { 2 - 7 } & B & 6.0 & 5.95 & 99.16 & 0.007 \\
\hline Rice & A & 3.0 & 2.96 & 99.16 & 0.021 \\
\hline
\end{tabular}

\section{Conclusion}

The present part describes the detailed study of electrochemical reduction of $-\mathrm{C}=\mathrm{C}$ - group containing pesticides such as phenothrin and binapicryl from the results obtained from cyclic voltammetry, differential pulse adsorptive stripping voltammetry, millicoulometry and controlled potential electrolysis in methanol as solvent in the supporting electrolytes of $\mathrm{pH}$ ranging 2.0 to 6.0. From the experimental outcomes, it is decided that phenothrin and binapicryl is found to give a single well defined wave in the $\mathrm{pH}$ range 2.0 to 6.0. But binapicryl reduces at low negative potentials comparitive because of aromatic environment nearer to the electro active group .because of aromatic environment electron defficiancy occurs at the electro active group and the reduction readily takes 
place. In case of phenothrin it is different because of alicyclic environment nearer to the electro active group it will reduces at high reduction potentials. No reduction was observed in neutral and basic media. The waves/peaks of all the compounds in acidic media were due to the reduction of $-\mathrm{C}=\mathrm{C}$-group with addition of two electrons.

The electrode reaction mechanism of two compounds is found to be irreversible. The nature of the electrode process for all three compounds investigated are found to be diffusion controlled without any kinetic complications. The variation of diffusion current and peak current values with $\mathrm{pH}$ of the supporting electrolyte influence the diffusion coefficient values also to vary in the same manner. The diffusion current values obtained by cyclic voltammetry for three compounds are in good agreement. The reason for a slight variation in diffusion coefficients with an increase in the $\mathrm{pH}$ may be attributed to the decrease in the availability of protons. The forward rate constant values for the reduction of all the compounds are found to be high in more acidic media in all the techniques, because the protonated species gets reduced.

Analytical events are described for the quantitative determination of these compounds by using DP-AdSV. In the present exploration both standard addition and calibration methods are utilised for the determination of these pesticides in grains, water and soil samples. From the recoveries it has been observed that the proposed method described the successful application of electroanalytical techniques for scrutiny of these pesticides. It also demonstrates that DP-AdSV at CNTPE can be conveniently used for the quantitative determination of these pesticides in above described experimental conditions. Hence, the method proposed is crucial and may become an attractive alternative to chromatographic techniques which are more tedious and time consuming.

\section{References}

1. Yúfera EP, Carrasco Dorrien JM, Agricola Q (1977) Plaguicidasyfitorreguladores, ( $1^{\text {st }}$ edn), Alhambra, Madrid, p. 291.

2. Somasundaram L, Coats JR (1990) Pesticide Transformation Products Fate and Significance in the Environment, ACS Symposium Series at the $200^{\text {th }}$ National Meeting of the American Chemical Society, American Chemical Society, Washington, USA, pp. 26-31.

3. Perin RM (1995). In: G Best (Ed.), Pesticides-Developments Impacts and Controls. The Royal Society of Chemistry, UK, p. 180.

4. Chaaieri Oudou H, Bruun Hansen HC (2002) Chemosphere 49: 12851294.

5. Sioufi A, Sandrenan N, Dubois JP (1989) Determination of crotamiton in plasma and urine by high-performance liquid chromatography. J Chromatogr 494: 361-367.

6. Anton K, Bach M, Geiser AJ (1991) Chromatogr 553(1-2): 71-79.

7. Nishi H (1997) J Chromatogr 780(1-2): 243-264.

8. Schulz W, AndreSchreiber (1992) laboratory for operation control and research lands was servers or gung, Germany.

9. Mauro De Paoli, Taccheo Barbina M (1992) Pesticide Science 34(1): 61-63.

10. Bissacot DZ, Vassilieff I (1997) J Anal Toxicol 21(5): 397-402.

11. Sassine A, Moura S, Viviane M Léo, Oscar V.e.g.a. Bustillos (2004) J Anal Toxicol 28(4238): 241(4).

12. Ramesh A, Perumal E Ravi (2004) J Anal Toxicol 28(8): 660-667.

13. Chen ZM, Wang YH (1996) J Chromatography 754: 367-395.

14. Bankim S, Ashwini S (2010) Electrochimica Acta 55: 8638-8648.

15. Bankim S, Shaikh M, Pradeep M, Goutam L, Ashwini S (2013) Biosensors and Bioelectronics 39: 124-132.

16. Bankim S, Ashwini S (2011) J analyticachimica acta 706: 246-254.

17. Nayan G, Bankim S, Shashi K, Ashwini S (2010) Electrochimica Acta 56: 627-635.

18. Nayan G, Bankim S, Ashwini S (2011) Analytica Chimica Acta 703: 31 40.

Your next submission with Juniper Publishers
will reach you the below assets
- Quality Editorial service
- Swift Peer Review
- Reprints availability
- E-prints Service
- Manuscript Podcast for convenient understanding
- Global attainment for your research
- Manuscript accessibility in different formats
( Pdf, E-pub, Full Text, Audio)
- Unceasing customer service
Track the below URL for one-step submission
https://juniperpublishers.com/online-submission.php

